\title{
O REGISTO SEDIMENTAR EM TRÁS-OS-MONTES ORIENTAL NAS PROXIMIDADES DO LIMITE NEOGÉNICO/QUATERNÁRIO
}

\author{
D. INSUA PEREIRA
}

Resumo

Abstract

O estudo recente realizado em Trás-os-Montes oriental, tendo em vista a caracterização sedimentológica e geomorfológica e o enquadramento estratigráfico dos depósitos cenozóicos, permitiu individualizar um conjunto de unidades litostratigráficas, entre as quais a Formação de Aveleda que estabelece a transição entre o preenchimento neogénico das depressões e o entalhe fluvial quaternário (PEREIRA, 1997). Esta unidade corresponde a uma etapa independente gerada na sequência de uma ruptura sedimentar, relacionada quer com condições tectónicamente activas quer com a alteração das condições climáticas. Os sedimentos, de cor avermelhada, ocorrem em pequenos afloramentos onde são predominantes as litofácies conglomeráticas, com clastos que revelam maioritariamente um transporte reduzido e fontes alimentadores locais. Os clastos são suportados numa matriz lutítica ilito-caulinítica abundante. Litofácies e arquitectura dos depósitos sugerem o predomínio de derrames do tipo debris flow e corpos do tipo leque aluvial. Também a caracterização granulométrica e a mineralogia da fracção argilosa constituem bons critérios de identificação desta unidade, em face da abundância de fracção lutítica nas litofácies conglomeráticas e arenosas e da frequência de ilite e caulinite. A Formação de Aveleda ocorre em dois domínios geomorfológicos distintos: em domínio tectónicamente pouco activo, sobre uma importante superfície erosiva correspondente à superfície da Meseta Ibérica, onde a modificação das condições relativamente quentes e húmidas do Pliocénico, para condições menos quentes e maior sazonalidade, deve ter constituído o factor mais decisivo; no contexto do acidente tectónico de Bragança-Vilariça que limita a ocidente aquela superfície de erosão, os derrames na forma de leques aluviais constituíram a resposta essencialmente a uma ruptura tectónica, com reactivação das escarpas de falha. A Formação de Aveleda correlaciona-se com outros sedimentos descritos na Península Ibérica que sucedem à colmatação das bacias e depressões ibéricas e posterior desenvolvimento de uma fase importante de erosão da Meseta. De acordo com essas características e modelos propostos para outras regiões da Península Ibérica, admite-se que esta etapa suceda a uma ruptura tectónica com cerca de $2.0 \mathrm{Ma}$ e com influência significativa da crise climática referida a $2.5 \mathrm{Ma}$ e condições posteriores, incluindo a nova crise que marca formalmente o início do Quaternário a $1.8 \mathrm{Ma}$.

Palavras-chave: Litofácies, conglomerado, ilite, caulinite, leque aluvial, superfície de erosão, depressão tectónica, Neogénico, Quaternário, Formação de Aveleda.

Sedimentological and geomorphological characterisation of Cenozoic sedimentary cover of eastern Trásos-Montes in Northeast Portugal, has enabled the definition of a range of lithostratigraphic units (PEREIRA, 1997). One of these, the Aveleda Formation, occurs in small outcrops and establishes the transition between the depressions filled by Neogene sediments and the quaternary fluvial dissection. Aveleda Formation suggests a sedimentary break related with tectonic activity and climatic changes. A reddish matrix-support conglomerate is the most usual lithofacies. Short transport of sediments in debris flow and alluvial fans is deduced by the geometry of the deposits and lithofacies. Data like lithology and clasts shape, dimensional analysis and clay mineralogy is also good criterion for identifying this formation. Illitic-kaolinitic mud is predominant in the conglomerate matrix. Aveleda Formation occurs in two different geomorphologic positions: i) over an erosive surface, the Iberian Meseta, with little tectonic activity and resulting from the erosion of resistant relieves in the Meseta border; ii) in strike-slip depressions, associated to the Bragança-Vilariça tectonic accident, in the west limit of the Meseta. In the first domain, climatic changes, from previous Pliocene conditions, hot and humid, to more seasonal and cooller weather, must be seen as the fundamental factor. In the depressions, alluvial fans resulted from tectonic impulses, under the same seasonal climatic conditions. This sedimentary event is now identified in Northeast Portugal near the Douro Basin border, but it has been described in other basins of the Iberian Peninsula. According to all data, this Formation is developed after a tectonic break (about 2.0 Ma) and with large influence of the climatic crises at $2.5 \mathrm{Ma}$ and the following conditions, including the new crises at $1.8 \mathrm{Ma}$ in the Neogene/Quaternary boundary.

Keywords: Lithofacies, conglomerate, illite, kaolinite, alluvial fan, erosive surface, tectonic depression, Neogene, Quaternary, Aveleda Formation.

\section{INTRODUÇÃO}

Os depósitos sedimentares cenozóicos de Trás-os-Montes oriental, foram objecto de um trabalho de reconhecimento e caracterização que permitiu definir um conjunto de unidades litostratigráficas regionais, correlacionáveis com unidades definidas nas Bacias Cenozóicas do Douro (Espanha), Mondego, Tejo e Sado (PEREIRA, 1997). Foram propostos os modelos deposicionais para essas unidades, com base na caracterização sedimentológica e geomorfológica, bem como o seu enquadramento cronostratigráfico,

\footnotetext{
* Departamento de Ciencias da Terra, Universidade do Minho, Campus de Gualtar, 4709 Braga Codex, Portugal

E-mail: icaetano@ci.uminho.pt
} 
fundamentalmente por correlação com propostas apresentadas nas bacias referidas (Quadro I).

Do conjunto de unidades propostas para Trás-os-Montes oriental, a Formação de Aveleda individualiza-se com base quer em características sedimentológicas próprias quer no seu enquadramento geomorfológico.

Em relação com o enquadramento geomorfológico, os depósitos sedimentares que constituem a Formação de Aveleda, em geral vermelhos ou avermelhados, foram identificados em duas situações de ocorrência distintas:

- Sobre uma a superfície de erosão, representação regional da Meseta Ibérica e melhor definida a leste, onde é conhecida por Planalto Mirandês (fig. 1). Os depósitos encontram-se situados maioritariamente nas zonas marginais desta superfície, em ligação com relevos de resistência quartzítica. Pequenos afloramentos com espessura reduzida ocorrem em posição culminante, em zonas mais interiores desta superfície de erosão. Em diversas situações, ressaltos topográficos da superfície definida por estes depósitos, sugerem movimentos tectónicos verticais.

- Na base de relevos de origem tectónica, em geral depressões relacionadas com os acidentes tectónicos de Bragança-Vilariça-Manteigas e de Mirandela (fíg. 1). Ao longo do primeiro, de orientação geral NNE-SSW, o esforço compressivo orientado aproximadamente segundo N-S deu origem a algumas bacias de desligamento, como as de Bragança, Sta. Combinha ou Macedo de Cavaleiros (CABRAL, 1995).
$\mathrm{O}$ acidente de Mirandela, de orientação N-S, tem a expressão geomorfológica de um graben, com abatimento de blocos ao longo de falhas com a mesma orientação $\mathrm{N}-\mathrm{S}$, em resposta à distenção secundária E-W. Estes depósitos, sedimentologicamente semelhantes aos que ocorrem sobre a superfície de erosão, têm um enquadramente geomorfológico distinto.

Correlaciona-se a Formação de Aveleda com depósitos referidos sobre a Meseta Ibérica, estratigraficamente posicionados entre o topo do preenchimento neogénico das bacias e os primeiros níveis de terraço fluvial do Plistocénico. O reconhecimento desta etapa em Portugal tem sido referido por diversos autores e a sua individualização como sequência deposicional (SLD 14) foi recen-temente proposta (modificado de CUNHA, 1992; PIMENTEL, 1997; PEREIRA, 1997).

Sendo relativamente seguro afirmar que a etapa de sedimentação destes materiais se situa nas proximidades do limite Neogénico/Quaternário, maior precisão no seu enquadramento tem sido dificultada por múltiplos factores:

- Ausência de meios de datação dos depósitos, pouco espessos e azóicos;

- Incerteza quanto à existência de um ou mais episódios deposicionais;

- Confusão com depósitos das sequências deposicionais anteriores (Miocénico superior a Pliocénico superior);

- Indefinição quanto à posição do limite Neogénico/Quaternário.

\begin{tabular}{|c|c|c|c|c|}
\hline $\begin{array}{l}\text { Formação/ } \\
\text { Membro }\end{array}$ & $\begin{array}{c}\text { Modelo de } \\
\text { sedimentação }\end{array}$ & Enquadramento & Localização & Idade \\
\hline $\begin{array}{l}\text { Terraços do } \\
\text { Douro }\end{array}$ & Fluvial & $\begin{array}{l}\text { Terraços no encaixe fluvial; } \\
\text { drenagem exorreica }\end{array}$ & Vale do Douro & Plistocénico \\
\hline $\begin{array}{l}\text { F. de } \\
\text { Sampaio }\end{array}$ & $\begin{array}{l}\text { Leques } \\
\text { Aluviais }\end{array}$ & Limitado a um graben & Depressão Vilariça & Plistocénico \\
\hline F. Aveleda & $\begin{array}{l}\text { Leques } \\
\text { Aluviais } \\
\text { Debris flow }\end{array}$ & $\begin{array}{l}\text { Sobre o Planalto e em bacias } \\
\text { de desligamento }\end{array}$ & Diversa & $\begin{array}{c}\text { Próxima do limite } \\
\text { Neogénico/Quaternário }\end{array}$ \\
\hline F. Bragança/ & $\begin{array}{c}\text { Fluvial } \\
\text { entrançado }\end{array}$ & $\begin{array}{l}\text { Num paleovale fluvial } \\
\text { controlado por graben }\end{array}$ & $\begin{array}{l}\text { Depressão de } \\
\text { Mirandela }\end{array}$ & Pliocénico superior \\
\hline $\begin{array}{l}\text { F. Bragança! } \\
\text { M. Atalaia }\end{array}$ & $\begin{array}{c}\text { Fluvial } \\
\text { entrançado }\end{array}$ & $\begin{array}{l}\text { Encaixe fluvial em drenagem } \\
\text { endorreica; controlo }\end{array}$ & Diversa & $\begin{array}{l}\text { Miocénico superior } \\
\text { Pliocénico inferior }\end{array}$ \\
\hline $\begin{array}{l}\text { F. Bragança/ } \\
\text { M. Castro }\end{array}$ & $\begin{array}{l}\text { Fluvial } \\
\text { entrançado }\end{array}$ & $\begin{array}{c}\text { Encaixe fluvial em drenagem } \\
\text { endorreica; contrlo } \\
\text { tectónico }\end{array}$ & Diversa & Miocénico superior \\
\hline $\begin{array}{l}\text { F. Vale } \\
\text { Álvaro }\end{array}$ & $\begin{array}{l}\text { Leques } \\
\text { Aluviais }\end{array}$ & Em bacia de desligamento & $\begin{array}{c}\text { Depressões de } \\
\text { Bragança e Macedo }\end{array}$ & Eocénico-Oligocénico \\
\hline
\end{tabular}

Quadro I - Unidades litostratigráficas definidas em Trás-os-Montes oriental.

Table I - Lithostratigrafic units in eastern Trás-os-Montes (NE Portugal). 

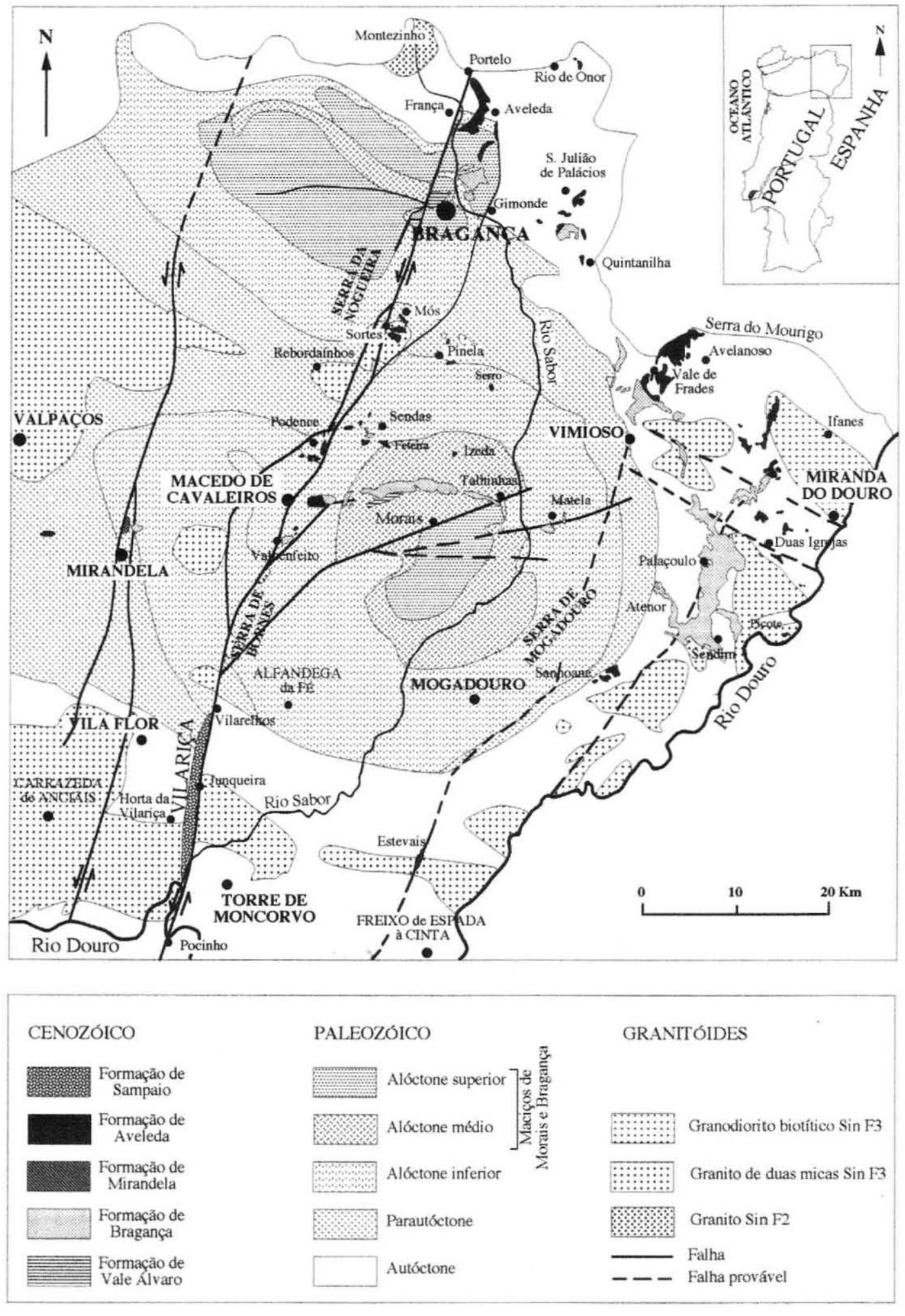

Fig. 1 - Localização dos depósitos cenozóicos em Trás-os-Montes oriental. Representam-se esquematicamente os dominios estruturais hercínicos e os afloramentos de granitóides.
Fig. 1 - Schematic map of eastern Trás-os-Montes (NE Portugal), showing Cenozoic deposits, Hercinian structural domains and granite outcrops. 
Na Península Ibérica, depósitos com características semelhantes às da Formação de Aveleda têm sido relacionados quer com uma ruptura tectónica conhecida por Ibero-Manchega II, com aproximadamente 2.0 Ma (PÉREZ-GONZÁLEZ, 1982; CALVO et ai, 1993) quer com condições de clima que contrastam com as condições quentes e húmidas precedentes, em geral condições de maior secura (AZEVEDO, 1993, PIMENTEL \& AZEVEDO, 1993), embora seja referido também um arre-fecimento favorável a processos de gelifracção nas montanhas periféricas da Meseta (AGUIRRE, 1997).

Por outro lado, observa-se a formalização do limite Neogénico/Quaternário, com a adopção do limiteestratotipo de Vrica e indicação do valor de $1.8 \mathrm{Ma}$ para este limite, correspondente a uma importante arrefecimento (PASINI \& COLALONGO, 1997). Dados globais confirmam também a ocorrência de uma importante crise climática há cerca de $2.5 \mathrm{Ma}$ (VAN COUVERING, 1997; NIKIFOROVA \& ALEKSEEV, 1997).

Descrevem-se nos capítulos seguintes as principais características da Formação de Aveleda e salientam-se os critérios que suportam o seu enquadramento estratigráfico.

\section{A FORMAÇÃO DE AVELEDA SOBRE \\ A SUPEREÍCIE DA MESETA}

A expressão Planalto Mirandês designa uma superfície aplanada e ligeiramente balanceada para sul, situada a oeste do curso internacional do rio Douro. O Planalto define-se sobre rochas granitóides e meta-sedimentares, essencialmente xistentas, do domínio Autóctone do NW Ibérico (fig. 1). Esta superfície, que está também conservada no nordeste da Beira, a leste do Côa, representa a continuação em Portugal da Meseta Norte, definida como uma superfície poligénica de aplanamento, também designada como peneplanície fundamental ou superfície fundamental; resulta de uma sequência de processos envolvendo o arrasamento de relevos, com preenchimento das depressões por sedimentos correlativos cenozóicos (FERREIRA, 1978; MARTÍN-SERRANO, 1988a). Contudo, é possível observar e individualizar um episódio sedimentar (Formação de Aveleda) posterior ao preenchimento destas depressões e a uma fase importante de desenvolvimento da superfície de aplanamento (PEREIRA, 1997). Esta superfície constitui assim a expressão morfológica da descontinuidade D5 da base da Formação de Aveleda (fig. 2 a 5).

A norte, o Planalto Mirandês é limitado pela Serra de Mourigo, um relevo residual constituído por cristas quartzíticas ordovícicas que se elevam cerca de 150 metros acima do aplanamento. O dobramento da série paleozóica faz salientar pequenas cristas que alimentam e limitam os afloramentos cenozóicos (fig. 2). A sul, a extensão do aplanamento reduz-se, termi- nando entre o Douro e a crista quartzítica da Serra de Mogadouro (fig. 3).

Para oeste, a continuidade do Planalto é interrompida pelo encaixe do rio Angueira e seus afluentes da margem esquerda. Ressaltos sucessivos da superfície topográfica e da superfície de suporte dos depósitos cenozóicos são justificados quer pelos acidentes tectónicos que limitam os mantos de carreamento do Alóctone e põem em contacto litologias diversas quer por movimentos verticais ao longo de falhas de orientação NE-SW e NW-SE. Mais para oeste, até ao acidente tectónico de Bragança-Vilariça, são identificadas porções mais ou menos conservadas da superfície da Meseta, sobre as quais podem ser também observados restos da Formação de Aveleda, nomeadamente em Rio de Onor, S. Julião de Palácios, Pinela, Lampaças, Feteira (Sendas) e Seixigal (Izeda) (fígs. 4 e 5).

Os sedimentos da Formação de Aveleda subsistem no Planalto Mirandês na forma de pequenos afloramentos de espessura reduzida (1 a 20 metros) cuja constituição traduz a natureza da fonte alimentadora a sua proximidade. Indicam-se alguns exemplos.

Na região de Vale de Frades (fig. 2) são predominantes as litofácies Gcm (conglomerados maciços, clasto-suportados) e Gmg (conglomerados com ciastes suportados pela matriz, com graduação inversa a normal) (MIALL, 1996), com predomínio da fracção limo-argilosa e alguns níveis lutíticos descontínuos intercalados. Os clastos de quartzo e quartzito, com dimensões até $20 \mathrm{~cm}$, têm desgaste muito reduzido a norte (v.g. Três Marras); para sul, aos elementos quartzosos com desgaste ligeiramente acrescido, juntam-se um número significativo de filitos na fracção grosseira. Esta tendência caracteriza também a fracção arenosa com predomínio de grãos de quartzo poligranular, essencialmente angulosos a subangulosos a montante e predomínio de fragmentos de xisto mais a jusante. Esta variação na composição dos sedimentos acompanha a natureza litológica do substrato. $\mathrm{Na}$ fracção arenosa pesada predominam os opacos e a andaluzite sobre o zircão. Na fracção argilosa caulinite ou caulinite+ilite são largamente predominante, a vermiculite e os interestratificados expansivos e não expansivos são vestigiais e a goethite é relativamente abundante.

A par das características sedimentológicas que são indicativas de uma alimentação local, salienta-se ainda a morfologia razoavelmente conservada na base dos relevos da serra de Mourigo, aspectos que traduzem a origem em leques aluviais (fig. 1).

Em pleno Planalto, a mancha da Sra. do Nazo (v.g. Revolta) revela uma contribuição importante do manto de alteração desenvolvido sobre os granitos e os clastos evidenciam características mais distais do que em Vale de Frades (fig. 3). Os sedimentos caracterizam-se pelo predomínio de conglomerados com suporte elástico, maciços (Gcm), ou com estratificação horizontal incipiente (Gh) e leitos lutíticos 


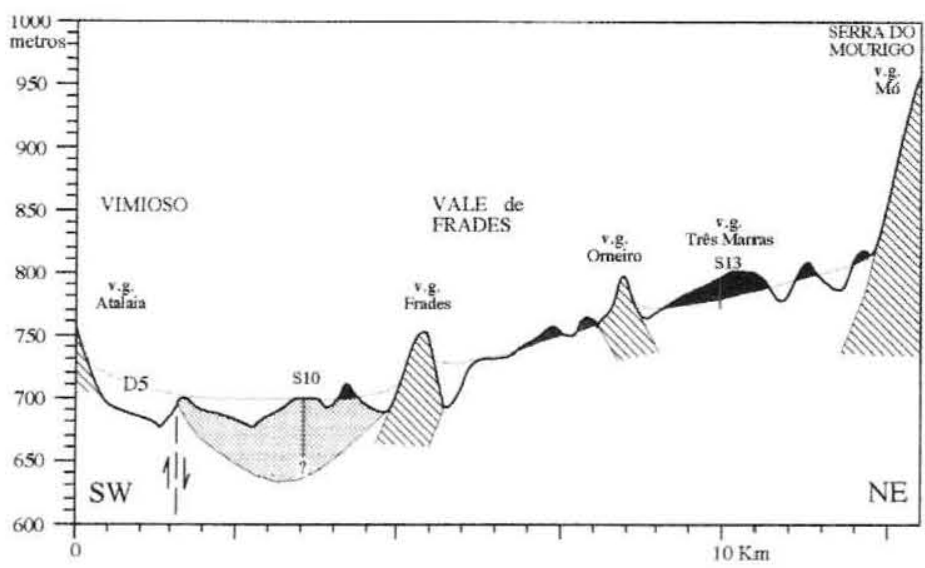

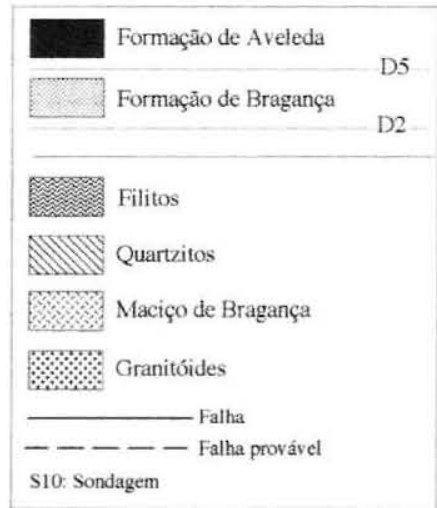

Fig. 2 - Perfil entre Vimioso (SW) e a Serra do Mourigo (NE). Na base, a Formação de Bragança preenche a depressão de Vimioso; a Formação de Aveleda situa-se no sopé das cristas quartzíticas (PEREIRA, 1997).
Fig. 2 - Cross section between Vimioso (SW) and Serra do Mourigo (NE). Bragança Formation fills Vimioso depression; Aveleda Formation is located at the foot of quartzitic hills (PEREIRA, 1997).

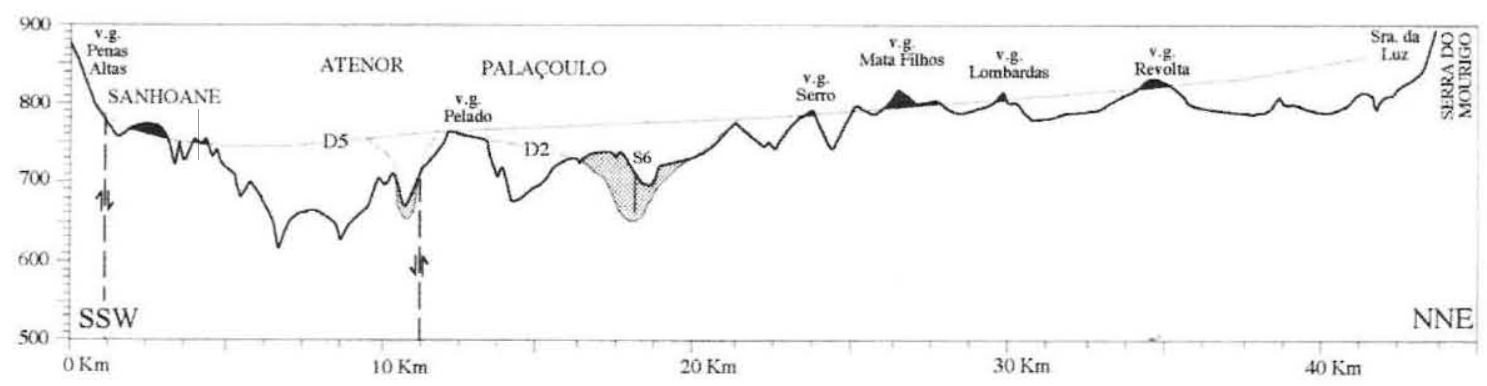

Fig. 3 - Perfil entre a Serra de Mogadouro (v.g. Penas Altas) (SSW) e a Serra do Mourigo (NNE). A Formação de Bragança preenche dois paleocanais no Planalto Mirandês; a Formação de Aveleda é posterior a uma superfície erosiva, basculada para o quadrante sul (PEREIRA, 1997). Legenda da Fig. 2.
Fig. 3-Cross section between Serra de Mogadouro (v.g. Penas Altas) (SSW) and Serra do Mourigo (NNE). Bragança Formation fills two fluvial palaeochannels in Miranda do Douro Upland; Aveleda Formation follows the erosive surface dipping south (PEREIRA, 1997).

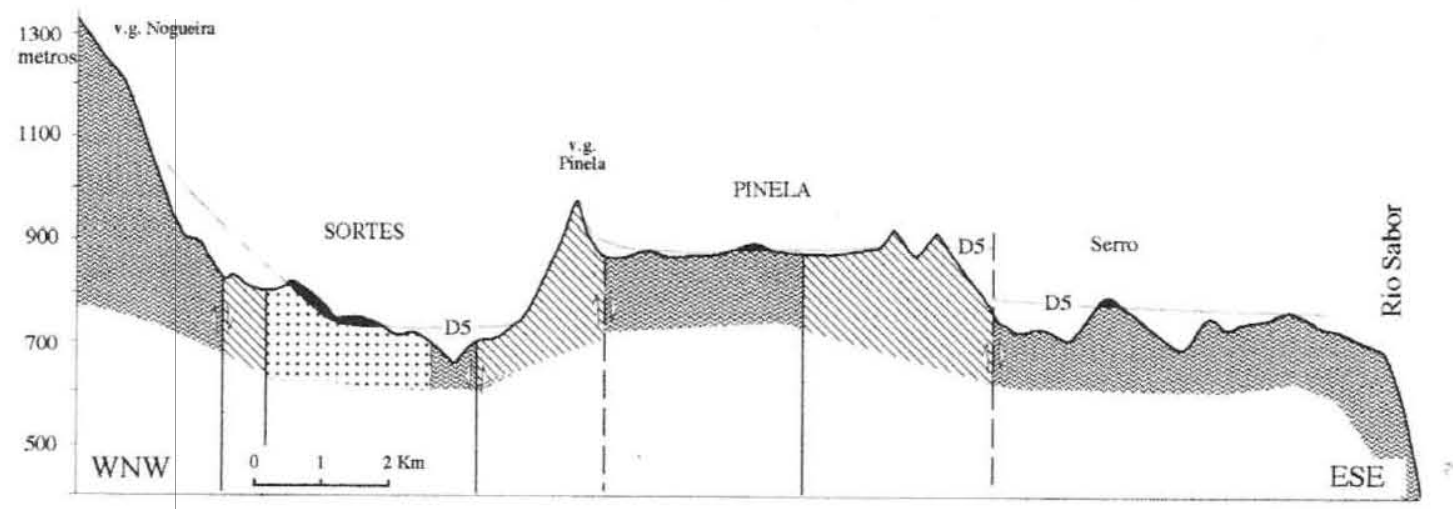

Fig. 4-Perfil realizado entre a serra da Nogueira (WNW) e o rio Sabor (ESE). Das superficies de aplanamento salientam-se os relevos residuais quartzíticos. É particularmente evidente o abatimento do bloco correspondente ao acidente tectónico Bragança-Vilariça, com os depósitos de Sortes, relativamente à superficie aplanada de Pinela (PEREIRA \& AzevÊdo, 1993b; Pereira, 1997). Legenda da Fig. 2.
Fig. 4-Cross section between Serra da Nogueira (WNW) and Sabor river (ESE). Quartzitic hills stand out erosive surfaces of Pinela and Serro and supply Aveleda Formation. Sediments of Aveleda Formation also fill Sortes tectonic depression (PEREIRA \& AZEVÊdo, 1993b; PEREIRA, 1997). 


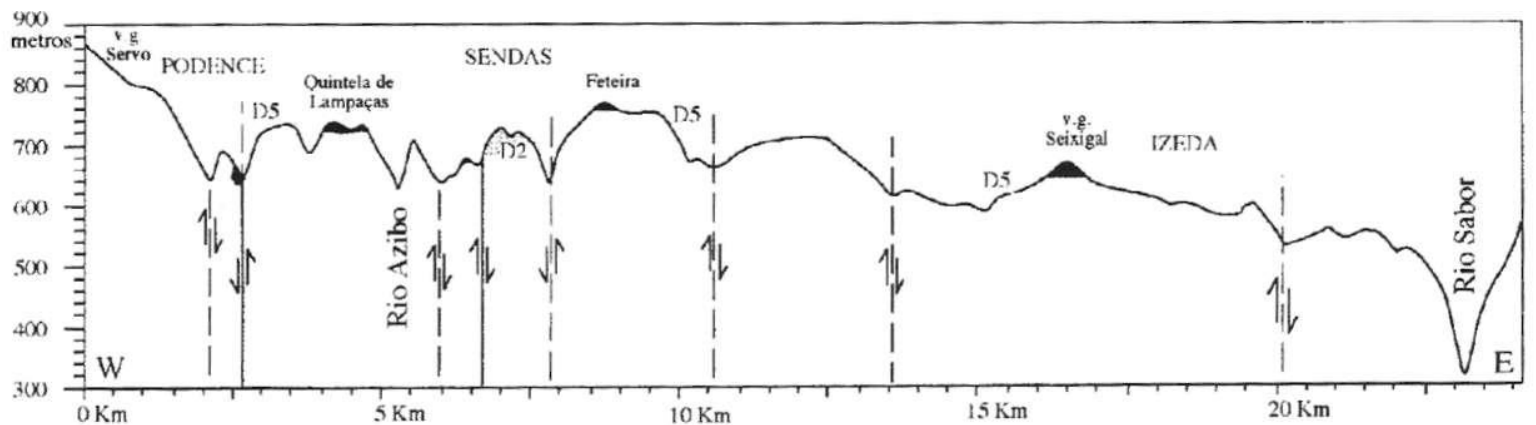

Fig. 5 - Perfil realizado entre o flanco sul da serra da Nogueira (W) e o rio Sabor (E). Evidencia-se a diferença no posicionamento dos sedimentos: a Formação de Bragança preenche a depressão de Sendas; a Formação de Aveleda, dispõe-se sobre uma superficie de aplanamento posterior. Legenda da Fig. 2.
Fig. 5 - Cross section between Serra da Nogueira (W) and Sabor river (E). Bragança Formation fills Sendas depression and Aveleda Formation follows the erosive surface.
(F1) mais abundantes para o topo. Os conglomerados têm largo predomínio da fracção lutítica sobre a fracção arenosa. Os clastos, do tipo subrolado, não ultrapassam $15 \mathrm{~cm}$ de dimensão e apresentam também desgaste superior relativamente ao caso anterior. A forte influência do substrato granítico sobre o qual assenta este depósito é revelada pela frequência de feldspatos, embora alterados. Esta fácies é predominantemente caulinítica, com ilite, goefhite e vestígios de interestratificados expansivos.

Um conjunto de pequenos afloramentos como os de v.g. Lombardas, v.g. Mata Filhos e v.g. Serro, constituídos por clastos angulosos ou subangulosos numa matriz vermelha, dispõem-se por todo o Planalto até Picote, supostamente resultantes do desmantelamento de alguns relevos residuais, no processo que conduz ao aplanamento (fig. 3).

Os dois pequenos retalhos sedimentares de Rio de Onor situam-se no interflúvio dos rios Maçãs e Onor, a NW do Planalto Mirandês e a leste de Bragança (fig. 1). Constituem reduzidos vestígios da Formação de Aveleda dispostos sobre uma superfície elevada, a cerca de 920 metros, retalhada pela actual rede de drenagem. Estes depósitos apresentam uma posição topográfica dominante e tiveram origem nas Serras da Barreira Branca e da Culebra (Espanha), situadas a leste e a NE (PEREIRA \& AZEVEDO, 1991; 1993a). O material é predominantemente conglomerático e tem uma espessura de aproximadamente 20 metros. Os clastos, angulosos e subangulosos de quartzo e quartzito, têm um tamanho máximo de $40 \mathrm{~cm}$ e são suportados por uma matriz de cor vermelha intensa, onde é dominante a fracção lutítica. Salienta-se a presença de alguns seixos de siderite, explicável pela ocorrência deste carbonato de ferro em massas associadas às cristas quartzíticas ordovícicas das serras de Barreiras Brancas e da Culebra e que constituíram o jazigo de ferro de Guadramil.
Outras manchas da Formação de Aveleda podem ser observadas em posição culminante, entre o acidente tectónico de Bragança-Vilariça e o rio Sabor. O desnivelamento das superfícies de base é de difícil interpretação: ou é devido a movimentações verticais ao longo de falhas, ou correspondente à sucessão de episódios distintos (fig. 4 e 5). As pequenas manchas de Pinela e Parada (v.g. Serro), são constituídas por sedimentos dispostos sobre uma superfície aplanada e ligam-se a relevos quartzíticos ou ocupam pequenas elevações (fig. 3). O manto aluvial pouco espesso preservado nas imediações de Pinela (cerca de $12 \mathrm{Km}$ a sul de Bragança) é essencialmente constituído por um conglomerado fino, com clastos de quartzo e quartzito, dispostos numa matriz essencialmente lutítica abundante e marcadamente vermelha, com predomínio de caulinite e ilite; embora assente sobre fácies xistosas paleozóicas, a sua origem encontra-se fundamentalmente nas fácies quartzíticas que constituem pequenas cristas (PEREIRA \& AZEVEDO, $1991 ; 1993 \mathrm{a})$

$\mathrm{Na}$ mancha sedimentar de Feteira, situada entre Sendas e Vinhas (fig. 5), observam-se clastos de quartzo, com alguns quartzoliditos e quartzitos, suportados por uma matriz abundante, predo-minantemente lutítica. Os blocos de maior dimensão, que atingem $50 \mathrm{~cm}$, situam-se a NW, diminuindo o seu tamanho para SW. Este facto indica uma origem provável a $\mathrm{NW}$, hipótese apoiada pela forma como esses blocos preenchem um entalhe no substrato, aspecto que confere à mancha sedimentar uma forma em V, de vértice dirigido para a origem, pelo que se admite tratarse de um pequeno cone aluvial.

Em síntese, neste contexto do Planalto Mirandês e seu prolongamento para ocidente, os depósitos da Formação de Aveleda são alimentados essencialmente por relevos quartzíticos que se salientam na periferia da superfície de aplanamento. 
3. A FORMAÇÃo DE AVELEDA NO CONTEXTO DO ACIDENTE TECTÓNICO BRAGANÇA-VILARIÇA

O acidente tectónico Bragança-Vilariça está definido entre Portelo, na fronteira a norte de Bragança, e o vale da Vilariça (fig. 1). Tem continuidade para sul até Manteigas, mantendo uma orientação aproximada NNE-SSW. Em zonas em que a movimentação se efectuou ao longo de falhas paralelas ou mesmo oblíquas relativamente à orientação principal, definem-se depressões tectónicas associadas ao acidente. A mais expressiva é a depressão tectónica da Vilariça, limitada a leste por uma vertente abrupta, correspondente a uma escarpa de falha com 300 a 400 metros de altura. A norte da Vilariça diferenciam-se as depressões de Bragança e de Macedo de Cavaleiros e as pequenas depressões de Sortes-Mós (fig. 4) e de Podence-Sta. Combinha (fig. 5). Estas depressões são referidas como bacias de desligamento e têm origem na reactivação alpina de acidentes hercínicos, com uma importante componente de movimento horizontal. Constituíram zonas de acumulação e conservação de sedimentos cenozóicos, cuja erosão tem vindo a ser efectuada pelo encaixe da rede fluvial actual. A movimentação esquerda das falhas é também responsável pela edificação das Serras da Nogueira e de Bornes (CABRAL, 1995).

A depressão situada mais a norte desenvolve-se desde Portelo até um pouco a sul de Bragança. Nesta depressão diferenciam-se blocos limitados por falhas

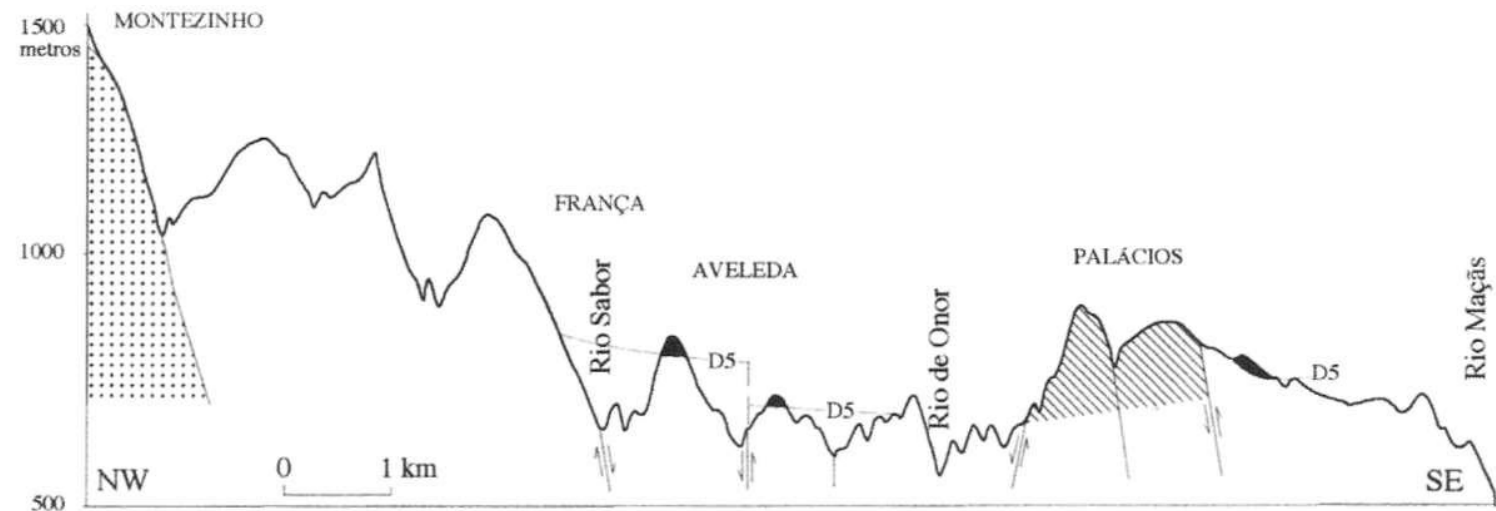

Fig. 6 - Representação da depressão tectónica associada ao acidente Bragança-Vilariça, a norte de Bragança. Evidencia-se a posição da Formação de Aveleda neste graben e na região de Palácios (Pereira, 1997). Legenda da Fig. 2.

Fig. 6 - Tectonic depression related to the Bragança-Vilariça accident. Aveleda Formation occurs in this graben and in Palácios area (PEREIRA, 1997).

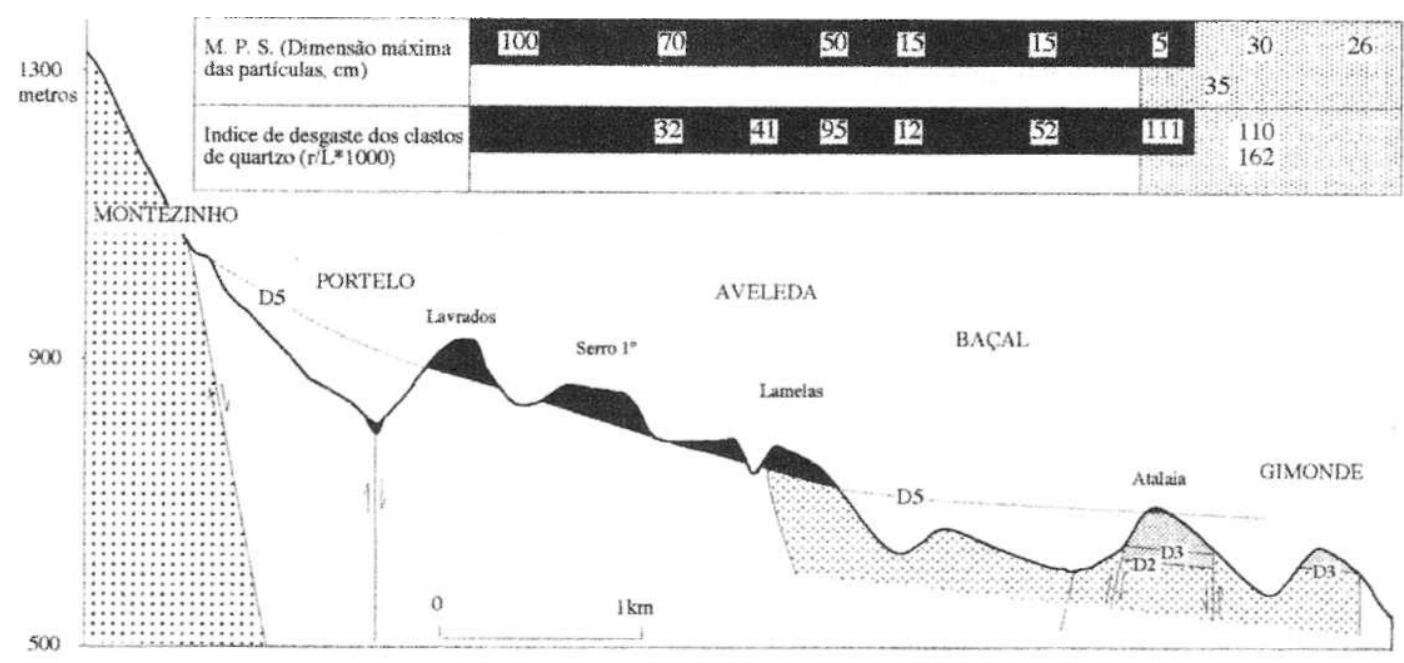

Fig. 7 - Perfil diagonal ao acidente tectónico Bragança-Vilariça a norte de Bragança; representam-se as Formações de Bragança e de Aveleda, bem como a variação do M.P.S. e do desgaste dos clastos ao longo do perfil (PEREIRA \& AZEVÊDO, 1991; Pereira, 1997). Legenda da Fig. 2.
Fig. 7 - Cross section in north Bragança area, diagonal to Bragança-Vilariça tectonic accident. M.P.S. and roundness index were determined for Bragança and Aveleda Formations (PEREIRA \& AZEVÊDO, 1991; PEREIRA, 1997). 
diversas, cuja movimentação é evidenciada pelo desnivelamento das superfícies que suportam a Formação de Aveleda (fig. 6). O bloco situado mais a norte, entre Aveleda e Baçal, suporta os depósitos de Aveleda cuja superfície de base (descontinuidade D5) apresenta um elevado declive (fig. 7). Esta descontinuidade define-se quer sobre o substrato, sem qualquer ressalto morfológico entre as rochas do Autóctone e do Alóctone, quer sobre o Membro de Atalaia da Formação de Bragança (PEREIRA \& AZEVEDO, 1993a).

$\mathrm{Na}$ Formação de Aveleda são salientes os blocos que atingem 1 metro de dimensão a montante (NNW), com rápido decréscimo para jusante (fig. 7). Predominam os blocos de quartzo, num conjunto que inclui também quartzoliditos e quartzitos. A matriz dos conglomerados é essencialmente limo-argilosa de cor vermelha, muito abundante nas litofácies Gmm. Nas litofácies Gh a imbricação é evidente, por influência do elevado achatamento dos calhaus subangulosos de filitos e quartzitos. Intercalados, ocorrem raros níveis lutíticos, com areia e areão e seixos muito dispersos.

As características sedimentológicas e o enquadramento morfo-tectónico da Formação de Aveleda no contexto da depressão de Portelo-Bragança ilustram um modelo sedimentar do tipo leque aluvial. Admite-se que o ápice deste cone se tenha situado a norte, na zona de Portelo, orientado para SSE, prependicularmente à escarpa de falha. A partir daí, a disposição do corpo terá sido condicionada pela orientação da depressão, inflectindo para sul (fig. 1).

Entre o Maciço de Bragança e o maciço granítico de Rebordaínhos, toma forma uma pequena depressão, limitada a oeste pela Serra da Nogueira (fig. 4). Os sedimentos que aí ocorrem, revelam duas origens distintas, pelo que se designam, de acordo com a sua localização, por depósitos de Mós e depósitos de Sortes (fig. 1). As características sedimentológicas destas depósitos não facilitam o seu enquadradamento estratigráfico em qualquer uma das unidades até ao momento consideradas, embora apresentem maiores afinidades com a Formação de Aveleda. Situam-se no contexto do acidente Bragança-Vilariça e relacionamse com uma fase de soerguimento da Serra da Nogueira. Os materiais das manchas de Sortes têm origem principalmente no maciço granítico de Rebordaínhos e nas fácies quartzíticas envolventes da Serra da Nogueira, tendo-se depositado após um percurso curto, na ordem dos $2 \mathrm{~km}$ de extensão. Representam a deposição na base da serra, com grandes blocos em situação proximal e decréscimo da dimensão para leste, acompanhado por variação na composição e organização sedimentar. Os sedimentos que constituem os depósitos da mancha de Mós, confirmam uma origem distinta relativamente aos anteriores, situada no sector NE da Serra da Nogueira. Os dados sugerem um corpo torrencial, com leito encaixado no substrato, estreito e relativamento espesso.
Os depósitos de Podence-Sta. Combinha (fig. 5) e de Castelãos situam-se a leste de Macedo de Cava-leiros, na dependência do acidente Bragança-Vilariça (PEREIRA \& AZEVEDO, 1991; 1993a; PEREIRA \& AZEVEDO, 1993b). São materiais predominantemente conglomeráticos, com níveis lutíticos descontínuos, em geral de cor vermelha. O desgaste reduzido das partículas e a sua organização, revelam sempre um curto transporte em mantos do tipo debris-flow. As características dos sedimentos e a relação geomorfológica que evidenciam com as formas de relevo actual, são os critérios que sugerem o seu enquadramento na Formação de Aveleda.

Em Castelãos, esta unidade é ravinante sobre a Formação de Bragança. A arquitectura deposicional e as características proximais são semelhantes às observadas a norte, na região de Podence-Sta. Combinha. Os sedimentos preenchem pequenas bacias de desligamento e são correlativos com uma fase de reactivação compressiva do acidente Bragança-Vilariça e levantamento das serras da Nogueira e de Bornes. Um fase de movimentação posterior encontra-se patente nos cortes observados, com contactos abruptos entre substrato e depósito, milonitização no contacto, verticalização de clastos e alteração das estruturas sedimentares originais.

\section{CRITÉRIOS SEDIMENTOLÓGiCOS DE IDENTIFICAÇÃO DA FORMAÇÃO DE AVELEDA}

Do conjunto de características sedimentológicas que foi possível definir para a Formação de Aveleda em trabalhos anteriores (PEREIRA \& AZEVEDO, 1991; 1993a; 1993b; PEREIRA, 1997), selecionam-se agora a identificação das litofácies, os aspectos texturais e a mineralogia da fracção <2|im, por constituírem critérios de mais fácil quantificação e consequente distinção relativamente a outras unidades regionais.

\subsection{LITOFÁCIES E TEXTURAS}

Os depósitos da Formação de Aveleda são essencialmente conglomeráticos, com matriz predominantemente lutítica, exprimindo o carácter de suporte matricial de parte significativa dos níveis sedimentares (Fig. 8). Os clastos, maioritariamente angulosos e subangulosos, de quartzito, quartzo e por vezes de filitos, revelam transporte reduzido.

Os níveis predominantemente lutíticos intercalados nos conglomerados são estreitos e pouco frequentes e caracterizam-se pela presença habitual de uma subpopulação de pequenos seixos (fig. 8). Os níveis mais arenosos são raros e revelam também eles uma frequência elevada de partículas lutíticas. Esta abundância de partículas finas, traduz-se na proximidade dos valores médios das litofácies Gh (conglomerados 


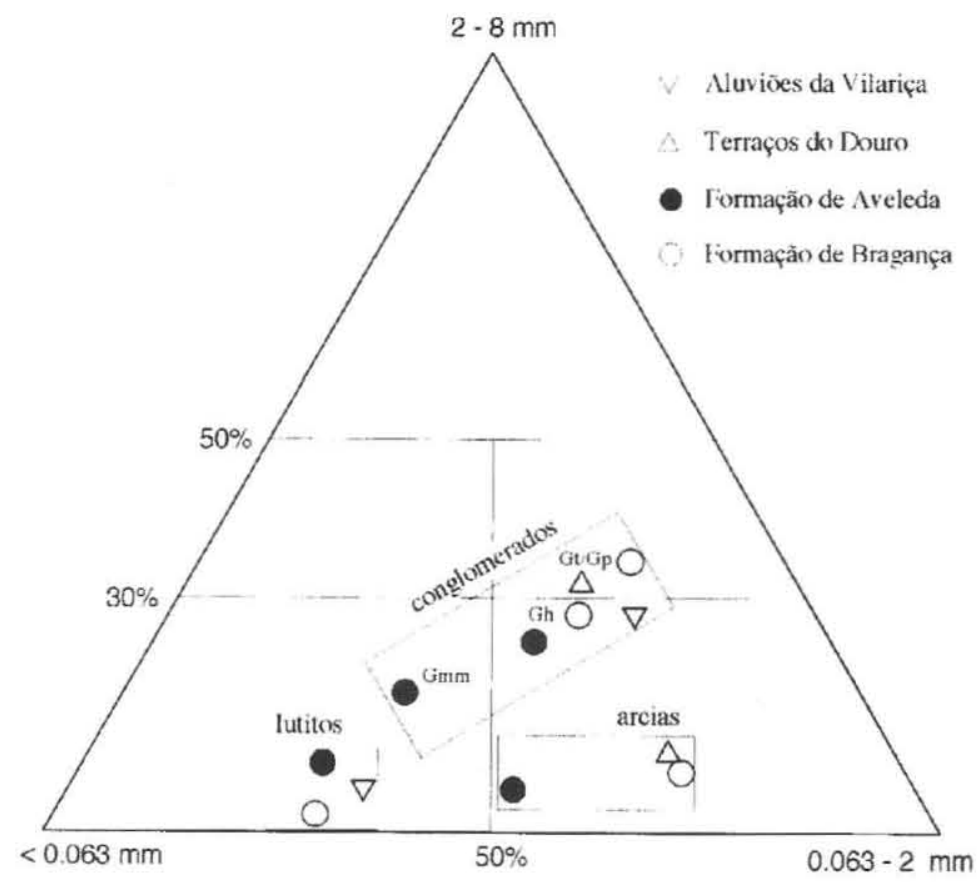

Fig. 8-Caracterização das diferentes litofácies da Formação de Aveleda em função da sua constituição média nas fracções granulométricas $2-8 \mathrm{~mm}, 0.063-2 \mathrm{~mm}$ e $<0.063 \mathrm{~mm}$; a elevada frequência de fracção lutítica nas litofácies conglomeráticas e arenosas distingue a Formação de Aveleda relativamente às outras unidades.
Fig. 8-Textural characterization of lithofacies of Aveleda Formation; large frequency of mud in conglomerate and sand lithofacies distinguish Aveleda Formation from others units.

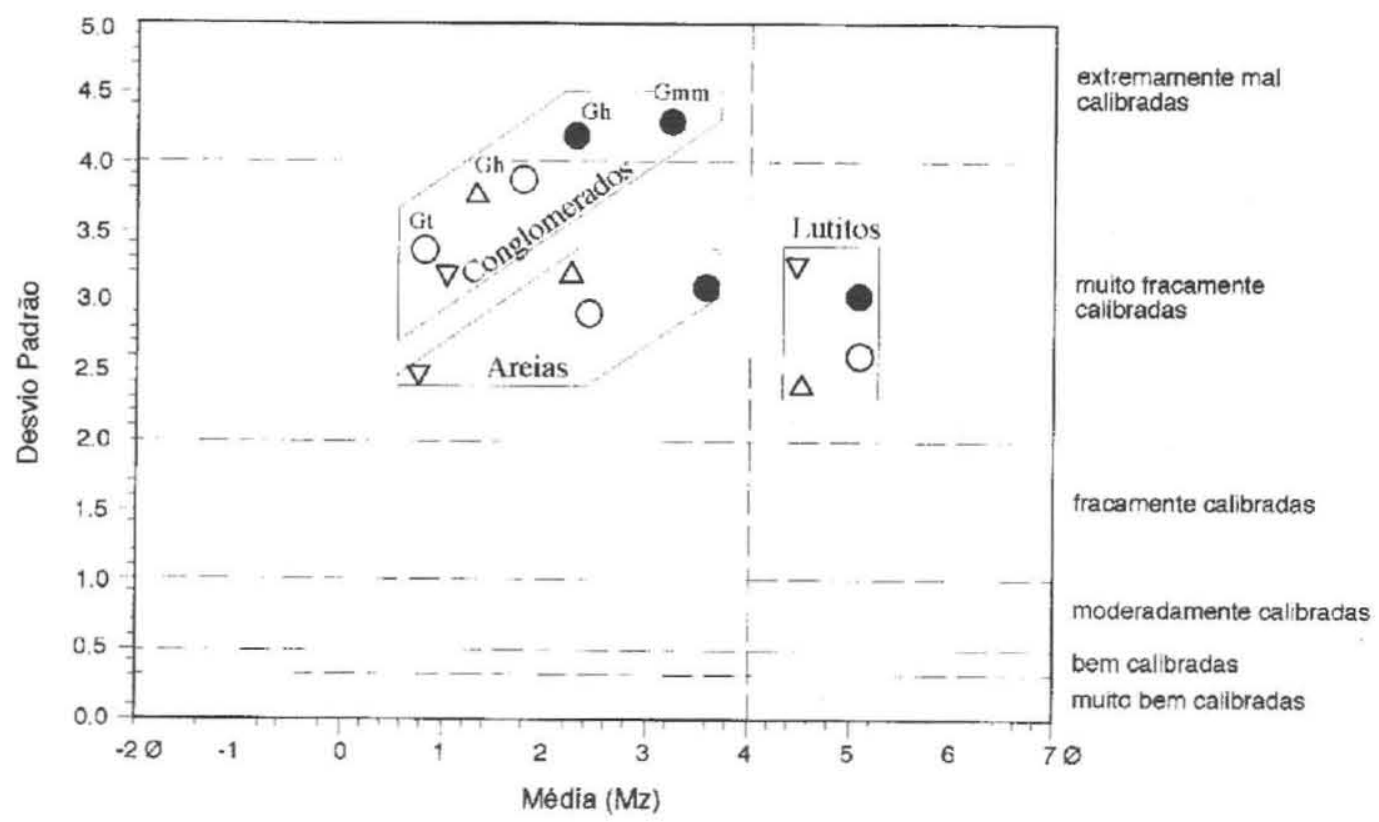

Fig. 9-Caracterização das diferentes litofácies da Formação de Aveleda em diagrama média versus desvio padrão (FoLK \& WARD, 1957); idem para outras unidades com fim comparativo. Legenda da figura anterior.
Fig. 9 - Scatter plot of mean size versus standard deviation; data obtained from different lithofacies (mean value) of Aveleda Formation and others units. 
com suporte elástico e estratificação incipiente), Gmm (conglomerado maciço com suporte da matriz) e Fm (lutitos maciços) no diagrama triangular, ocupando posições relati-vamente próximas (fig. 8).

Os conglomerados da Formação de Aveleda revelam pior calibragem quando comparados com as mesmas fácies das restantes formações definidas em Trás-os-Montes (fig. 9). A má calibragem resulta essencialmente do carácter bimodal da distribuição, representando $\mathrm{Mz}$ a média aritmética das duas modas, uma correspondente às partículas finas e outra às partículas grosseiras; a mistura e consequente má calibragem são interpretados como resultantes da falta de eficácia na selecção durante o transporte, sobre as dimensões fornecidas pela área-mãe (FOLK \& WARD, 1957; ALVES, 1995). Assim, diferenciam-se as unidades e as condições de transporte e sedimentação, especialmente com base nas litofácies conglomeráticas.

Evidencia-se assim para a Formação de Aveleda, a má calibragem, o carácter bimodal e platicúrtico da distribuição dimensional, características de fluxos do tipo debris flow viscosos e debrisflow fluídos (WELLS \& HARVEY, 1987). Estes fluxos resultam de diferentes relações água/sedimento e têm correspondência respectivamente com as litofácies Gmm e Gh. É também admissível que no caso da Formação de Aveleda os níveis mais finos resultem essencialmente de fluxos do tipo mudflow, modelo bem diferente do observado na Formação de Bragança, na qual a acumulação de finos está associada a fácies de transbordo (FF) e a preenchimentos de canais devido ao seu abandono ou quebra da energia de transporte $(\mathrm{FF}(\mathrm{CH}))$.

\subsection{MINERALOGIA DA FRACÇÃO $<2$ um}

A Formação de Aveleda caracteriza-se pelo predomínio de ilite e caulinite na fracção <2um, observando-se contudo diferenças de acordo com o contexto geomorfológico considerado (fig. 10). Nas situações em que os depósitos estão conservados nas depressões, evidenciam um maior predomínio de ilite e a presença pouco abundante de minerais argilosos expansivos, fundamentalmente interestratificados ilite-esmectite. Nas situações em que ocorrem em posição dominante, sobre a superfície do Planalto, aumenta a frequência de caulinite, diminui a ilite e tornam-se ausentes ou quase ausentes os minerais expansivos.

Nas situações em que é dominante, a ilite revela boa cristalinidade. Em posição de planalto esta situação é também evidente nos níveis lutíticos intercalados nos conglomerados, factos que sugerem condições pouco propícias para a hidrólise nos perfis de meteorização que alimentaram o depósito. Nos níveis conglomeráticos superficiais da Formação de Aveleda é observada a abertura da estructura da ilite, acompanhada pela formação de interestratificados ilite-

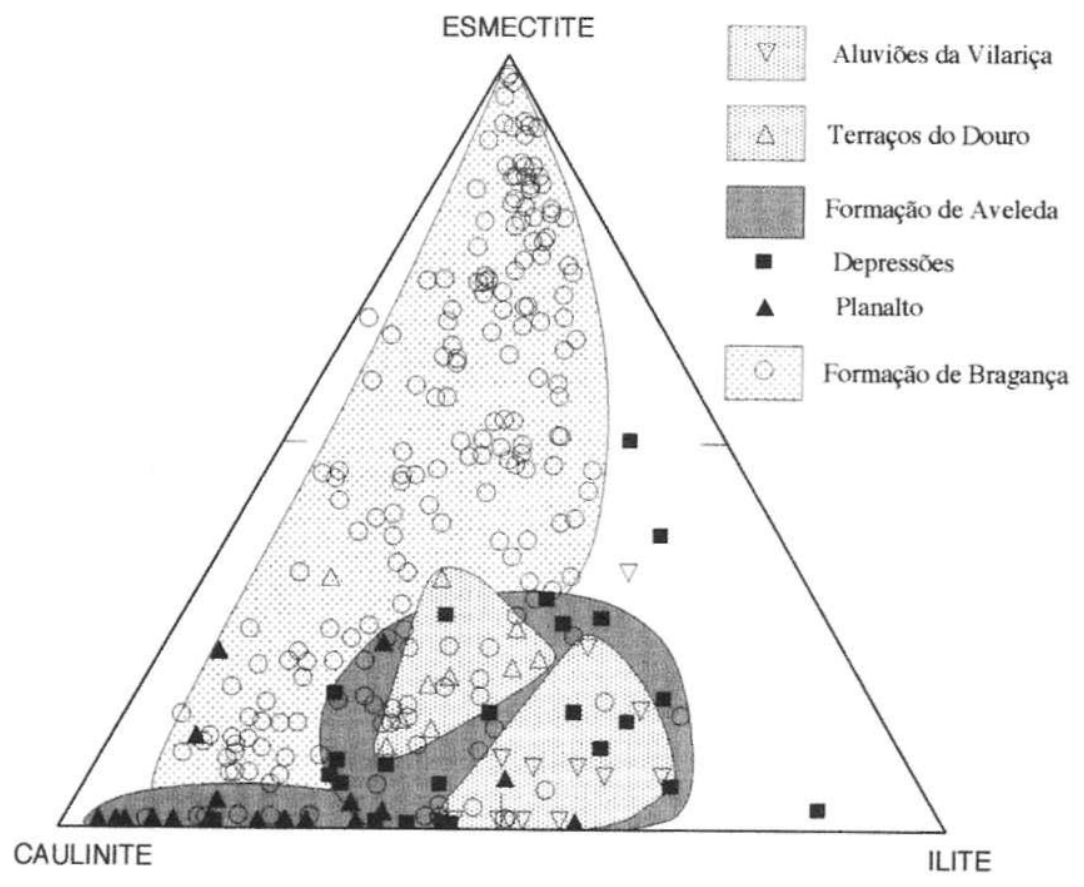

Fig. 10 - Frequência relativa em esmectite (incluindo interestratificados com esmectite), caulinite e ilite da fracção $<2 \mu \mathrm{m}$, das amostras da Formações de Aveleda e comparação com outras unidades regionais.
Fig. 10 - Differences between the Aveleda Formation and other units in relation to the smectite, kaolinite and illite contents. 
vermiculite e vermiculite e pelo aumento relativo da caulinite. Estas modificações, traduzidas principalmente pelo aumento de caulinite e ilite-vermiculite, por processos de transformação e neoformação a partir da fracção detrítica original, maioritariamente constituída por ilite de boa cristalinidade, resultam da evolução pedológica de solos fersialíticos (DELGADO et al, 1990; DELGADO et al, 1994; MARTín-GARCíA et al, 1997). O aumento da caulinite observado nas proximidades da superfície, quer em perfis sedimentares quer em perfis de alteração desenvolvidos sobre o substrato, é também evidenciado nas restantes formações definidas em Trás-os-Montes. Revela-se um processo de alteração funcional ao longo do Quaternário e até à actualidade.

\section{MODELOS DEPOSICIONAIS}

Uma parte significativa dos depósitos da Formação de Aveleda caracteriza-se pela reduzida espessura, pelo maior desenvolvimento na base de relevos e por sucederem a uma fase de aplanação que corta em continuidade o substrato e o enchimento das depressões, representado pela Formação de Bragança. Estão nestas condições as ocorrências do Planalto Mirandês e outras situadas mais para ocidente.

Em alguns casos interpretaram-se condições em que depósitos semelhantes ocupam posição na base de pequenas depressões em sectores do acidente tectónico Bragança-Vilariça. Em face dessa posição, evoluíram em condições de drenagem deficiente, favorecendo a conservação da mineralogia original e eventualmente da formação de alguns interestratificados expansivos.

Assim, após a colmatação das depressões terciárias deverão ter sucedido condições de menor actividade tectónica, observando-se o maior desenvolvimento da superfície de aplana- mento representada no Planalto Mirandês. Estas condições de tectónica pouco activa parecem ter permanecido até à actualidade nesta região em particular, permanecendo acima dessa superficie alguns relevos de resistência, especialmente as cristas quartzíticas das Serras de Mourigo e de Mogadouro.

Pelo contrário, ao longo dos principais acidente tectónicos, condições de tectónica mais activa foram responsáveis pelo acentuar dos desníveis e pelo deslocamento dos depósitos da Formação de Bragança nestes domínios. Rupturas abruptas de pendente favoreceram o desenvolvimento dos depósitos da Formação de Aveleda. Predominam as litofácies Gmm, conglomeráticas, com clastos quartzíticos subangulosos, por vezes de grande dimensão, suportados numa matriz abundante predominantemente lutítica. A fracção mais fina, com predomínio de ilite, revela traços de alguma imaturidade dos perfis de alteração iniciais. Estas características permitem considerar uma origem essencialmente em fluxos do tipo debrisflow viscosos, intercalados por ocasionais fluxos do tipo mud flow, também a forma de alguns corpos na base dos relevos sugere a presença de alguns leques aluviais gerados sob condições de clima árido ou com sazonalidade marcada (RACKOCKI, 1981; COLOMBO, 1989; LECCE, 1990; AZEVEDO, 1993). Um processo de alteração activo até à actualidade, conferiu a estes depostos um carácter mais caulinítico e uma coloração avermelhada.

\section{CORRELAÇÕES E PROPOSTA DE ENQUADR A MENTO ESTRATIGRÁFICO}

$\mathrm{Na}$ ausência de meios directos para a datação, a formulação de uma proposta de enquadramento estratigráfico da Formação de Aveleda assenta numa metodologia que combina:

- A definição dos limites possíveis, com base nas relações com outras unidades regionais

A Formação de Aveleda constitui uma etapa independente relativamente às etapas anteriores com características fluviais. Esta independência é confirmada pela presença de uma descontinuidade com valor regional, entre a Formação de Aveleda e as unidades subjacentes, correspondente à superfície de erosão que tem melhor desenvolvimento no Planalto Mirandês.

Esta descontinuidade é evidente relativamente à Formação de Bragança e menos evidente relativamente à Formação de Mirandela, pois esta última está limitada à depressão de Mirandela e não apresenta uma relação estratigráfica clara com a Formação de Aveleda. Assim, de acordo com os dados regionais, pode afirmar-se que a Formação de Aveleda é seguramente posterior à Formação de Bragança (Miocénico superior a Pliocénico inferior) e provavelmente posterior à Formação de Mirandela (Pliocénico superior) (Quadro I). As relações indicadas e as propostas de enquadramento das unidades mais antigas (PEREIRA, 1997) permitem situar a Formação de Aveleda entre o fim do Pliocénico e os primeiros terraços plistocénicos.

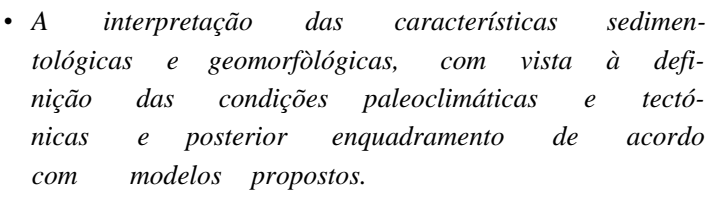

$A$ interpretação da arquitectura e dos modelos de sedimentação evidencia a sucessiva modificação das condições tectónicas e climáticas regionais. As etapas anteriores sugerem uma transição de condições relativamente temperadas e com sazonalidade, 
identificadas com o Miocénico superior (Formação de Bragança) para as condições de meteorização química mais intensa descritas para o Pliocénico e que estão na origem dos sedimentos da Formação de Mirandela (PEREIRA, 1997). Posteriormente, a relativa imaturidade dos materiais que alimentaram a Formação de Aveleda sugere solos pouco desenvolvidos sob condições de meteorização química pouco activas. Condições de aridez ou sazonalidade marcada são sugeridos pelo tipo de derrames identificados, do tipo debrisflow e geometrias do tipo leque aluvial.

A nível global têm sido referidos episódios maiores de arrefecimento entre 3.2 e 2.5 Ma (ZUBAKOV, 1990), com maior relevância a 2.5 Ma a que se sucedem condições de sazonalidade marcada para o fim do Pliocénico (VAN COUVERING, 1997). Estas condições são admissíveis no intervalo de tempo situado entre a preparação dos materiais e a mobilização dos sedimentos que constituem a Formação de Aveleda.

Uma etapa posterior, de alteração pós-deposicional foi responsável pela rubefacção e aumento da frequência da caulinite na Formação de Aveleda. Durante as fases interglaciares e nas condições de clima actual, este tipo de alteração é activa. Também as unidades mais antigas e os terraços plistocénicos do Douro revelam traços desta alteração.

A identificação de sedimentos com características semelhantes em ambientes tectónicos tão distintos como são o Planalto Mirandês e as depressões no contexto do acidente tectónico de Bragança-Vilariça, sugere que mais do que um episódio sedimentar pode estar presente. Sobre a Meseta, os sedimentos sucedem a uma etapa de relativa estabilidade tectónica e devem relacionar-se principalmente com condições de aridez ou sazonalidade climática.

Em situação distinta, no limite ocidental dos mais regulares aplanamentos da Meseta, o acidente tectónico de Bragança-Vilariça mantém uma actividade visível até à actulidade, como comprova o registo de diversos sismos históricos ao longo deste acidente. $\mathrm{Na}$ etapa correspondente à Formação de Aveleda, a combinação das condições climáticas referidas e o acentuar das depressões favoreceu a acumulação e preservação de sedimentos.

\section{- A correlação com unidades cronostratigráficas situadas nas proximidades}

Em algumas bacias sedimentares espanholas, algo distantes como a Bacia Superior do Tejo, é identificada uma ruptura sedimentar associada a um evento imediatamente anterior ao desenvolvimento do actual sistema fluvial. Esta ruptura, Ibero-Manchega II, é indicada na origem das extensas coberturas de sedimentos grosseiros do tipo Raña. Acima e abaixo da ruptura foram identificadas faunas do Vilafranquiano, critério fundamental de suporte para a indicação de uma idade próxima de 2.0 Ma (PÉREZGONZÁLEZ, 1982; CALVO et ai, 1993; AGUIRRE, 1997).
Na Bacia Superior do Tejo estes depósitos são referidos em vários níveis embutidos numa superficie erosiva definida sobre o topo do enchimento neogénico e anteriores aos primeiros terraços plistocénicos (PÉREZ-GONZÁLEZ \& GALLARDO, 1987).

$\mathrm{Na}$ Bacia do Douro, da qual a região transmontana constitui uma região periférica a ocidente, não são conhecidas datações dos episódios sedimentares que culminam o enchimento neogénico da bacia nem daqueles que possam constituir a transição para os primeiros terraços plistocénicos. E indicada uma etapa de leques aluviais situados na base das regiões montanhosas e que sela o enchimento neogénico (Martin-Serrano, 1988a). Para este autor a Raña tem um significado morfológico e corresponde aos primeiros níveis da fase de gliptogénese da bacia, não podendo ser associada a um episódio cronologicamente diferenciado (MARTIN-SERRANO, 1988b; 1989).

Em Portugal tem sido referida uma sequência independente que reflecte condições morfológicas e climáticas bem diferenciadas, representada desde Trás-os-Montes até ao Baixo Alentejo. Também a sul da região transmontana, esta etapa é observada como posterior a depósitos fluviais do Pliocénico superior e sucedendo a uma superfície que testemunha uma fase erosiva pré-raña importante e generalizada (AZEVEDO, 1993; PIMENTEL \& AZEVEDO, 1993; FERREIRA, 1993; CABRAL, 1995; PIMENTEL, 1997). Assim e apesar da ausência de critérios de datação destes depósitos, a fase de movimentação tectónica assinalada em Espanha (Ibero-Manchega II) tem sido indicada também em Portugal na origem desta sequência limitada por descontinuidade referida como SLD14 (CUNHA, com. oral; PIMENTEL; 1997), de acordo com proposta inicial de CUNHA (1992). Em zonas de maior estabilidade tectónica é admitido que uma crise climática possa estar na origem de depósitos deste tipo (CABRAL, 1995).

Na situação estudada em Trás-os-Montes, o reduzido desenvolvimento da Formação de Aveleda sobre a superfície de erosão, não traduz uma potencial origem tectónica, como no caso das largas extensões observadas nas proximidades de Madrid, na Bacia Superior do Tejo. São sedimentos semelhantes aos referidos do lado espanhol, na base dos relevos montanhosos na periferia da Bacia do Douro. Evidencia-se o facto de estes sedimentos sucederem à colmatação da bacia e ao desenvol-vimento de uma superfície erosiva.

No contexto do acidente tectónico de Bragança-Vilariça a origem tectónica é mais evidente. Contudo, tal como observado em bacias espanholas onde são indicados impulsos tectónicos que se prolongam nos primeiros tempos quaternários (AGUIRRE, 1997), diversos impulsos podem ter ocorrido estando na origem de corpos sedimentares que sucedem ao limite Neogénico/Quaternário formalmente indicado a 1.8 Ma (PASINI \& COLA-LONGO, 1997; NIKIFOROVA \& ALEKSEEV, 1997). 


\section{CONCLUSÕES}

A presença da Formação de Aveleda em contexto geomorfológicos distintos sugere uma etapa em que vários episodios de sedimentação se podem relacionar quer com condições climáticas específicas quer com actividade tectónica no contexto do acidente de Bragança-Vilariça. Após a colmatação das depressões pelos sedimentos neogénicos e sob condições de tectónica pouco activa, as modificações climáticas sentidas no fim do Pliocénico terão sido responsáveis pela erosão de relevos mais resistentes. Os sedimentos resultantes dispõem-se assim com maior espessura no sopé desses relevos e em condições mais favoráveis podem extender-se sobre a superfície de aplanamento já constituída. Ao longo do principal acidente que limita a Meseta a oeste, o acidente tectónico Bragança-Vilariça, impulsos tectónicos estão na origem de sedimentos apri-sionados em pequenas depressões. Todos estes sedimentos revelam características originais de imaturidade e uma evolução posterior sob condições de meteorização mais activa.

Não é possível indicar uma idade exacta para a Formação de Aveleda e unidades com que se correlaciona. Em algumas bacias espanholas dados paleontológicos têm indicado uma idade próxima de $2.0 \mathrm{Ma}$, mas quer nessas bacias quer na Bacia do Douro tem sido pouco aceite o modelo de um episódio isolado situado entre o colmatar das depressões e os terraços quaternários.

A análise dos dados obtidos em Trás-os-Montes e o conhecimento de outras situações, em particular nas Bacias do Douro e do Tejo, sugerem-nos uma etapa para a qual se deve estabelecer um intervalo entre o fim do Neogénico e o início do Quaternário. O desenvolvimento desta etapa é controlado por actividade tectónica, referida nas proximidades de $2.0 \mathrm{Ma}$ e condições climáticas específicas, possivelmente identificadas com as crises referidas a 2.5 e $1.8 \mathrm{Ma}$.

\section{B I B L I O G R A F I A}

AGUIRRE, E. (1997) - The Pliocene-Pleistocene transition in the Iberian Peninsula, in VAN COUVERTNG (Ed.), The Pleistocene Boundary and the Beginning of the Quaternary, World and Regional Geology, 9, Cambridge University Press., p. 169-177.

AZEVEDO, T. M. (1993) — La raña de Marco Furado (Península de Setúbal, al sur de Lisboa). La Raña en España y Portugal, Centro de Ciencias Medio-ambientales, Monografías, 2, Madrid, p. 51-58.

ALVES, I. C. (1995) - Materiais Plio-Quaternários do Alto Minho. Produtos de meteorização e depósitos fluviais na bacia do rio Lima e região de Alvarães. Tese de doutoramento. Universidade do Minho, Braga., 277 p.

CABRAL, J. (1995) - Neotectónica em Portugal Continental. Memórias do Instituto Geológico e Mineiro, 31, Lisboa, 265 p.

CALVO, J., DAAMS, R., MORALES, J., LÓPEZ-MARTÍNEZ, N., AGUSTI, J., ANADÓN, P., ARMENTEROS, I., CABRERA, L., CIVIS, J., CORROCIIANO, A., DÍAZ-MOLINA, M., ELIZAGA, E., HOYOS, M., MARTIN-SUAREZ, E., MARTíNEZ, J., MOISSENET, E., MUNOZ,
A., PEREZ-Garcia, A., PEREZ-GONZAlEZ, A., PORTERO, J., ROBLES, F., SANTISTEBAN, C, TORRES, T., VAN DER MEULEM, A., VERA, J.. \& MEIM, P. (1993) - Up-to-date Spanish continental neogene syntesis and paleoclimatic interpretation. Revista Sociedad Geológica de España, 6 (3-4), p. 29-40.

COLOMBO. F. (1989) - Abanicos aluviales, Sedimentologia. Nuevas Tendencias, 11, Consejo Superior de Investigaciones Científicas. Madrid.

CUNHA, P. (1992) - Estratigrafía e sedimentologia dos depósitos do Cretácico Superior e Terciário de Portugal Central, a leste de Coimbra. Tese de doutoramento. Universidade de Coimbra, $262 \mathrm{p}$.

DElGADO, R, PÁRRAGA, J., DElGADO, G, HUERTAS, F. \& LINARES, J. (1990) - Génese d'un sol fersiallitique de la Formation Alhambra (Granada-Espagne), Sei. Sol. 28, p. 53-70.

DELGADO, R, AGUILAR, J. \& DELGADO, G. (1994) - Use of numerical estimators and multivariate analysis to characterize the genesis and pedogenic evolution of Xeralfs from Southern Spain. Catena, 23, p. 309-325.

FERREIRA, A. B. (1978) - Planaltos e montanhas do Norte da Beira Estudo de geomorfologia. Memorias do centro de Estudos Geográficos, 4, Lisboa, 210 p.

FERREIRA, A. B. (1993) - As rañas em Portugal. Significado geomorfológico e estratigráfico, in G. S. CARVALHO, A. B. FERREIRA e J. C. SENNA-MARTINEZ (eds.), O Quaternário em Portugal, balanço e perspectivas, APEQ. Ed. Colibri. Lisboa, p. 7-15.

FOLK , R. \& WARD, W. (1957) - Brazos River Bar: a study in the significance of grain-size parameters, Journal of Sedimentaty Petrology, 27 (1), p. 3-26.

LECCE, S. (1990) - The Alluvial Fan Problem. In RACHOCKI \& CURCH (Eds.), Alluvial fans. A Field Approach, John Wiley \& Sons.

MARTIN-GARCIA, J., DELGADO, G, SANCHEZ-MARANON, M., PÁRRAGA, J. \& DELGADO, R. (1997) - Nature of dioctahedral micas in Spanish red soils. Clay Minerals, 32, p. 107-121.

MARTIN-SERRANO, A. (1988a) — El relieve de la región occidental zamorana. La evolución geomorfológica de un borde del Macizo Hespérico. Instituto de Estudios Zamoranos «Florian de Ocampo», Zamora, $311 \mathrm{p}$.

MARTÍN-SERRANO, A. (1988b) - Sobre la posición de la raña en el contexto morfodinámico de la Meseta. Planteamientos antigos y tendencias actuais. Boletín Geol. Min. España, 99, p. 855870.

MARTÍN-SERRANO, A. (1989) - Características, rango, significado y correlación de las Series Ocres del borde occidental de la Cuenca del Duero. Stud. Geol. Salmant. Univ. Salamanca, 5, p. 239-252.

MIALL, A. D. (1996) - The geology of fluvial deposits; sedimentary fácies, basin analysis and petroleum geology. Springer-Verlag, New York, 582 p.

PASINI, G. \& COLALONGO, M. L. (1997) - The Pleistocene boundary-stratotype at Vrica, Italy, in VAN COUVERING (ed.), The Pleistocene Boundary and the Beginning of the Quaternary. World and Regional Geology, 9, Cambridge University Press, p. 15-45.

PEREIRA, D. (1997) - Sedimentologia e Estratigrafia do cenozóico de Trás-os-Montes oriental, Tese de doutoramento. Universidade do Minho, $341 \mathrm{p}$.

PEREIRA, D. I. \& AZEVEDO, T. M. (1991) — Origem e evolução dos depósitos de cobertura da região de Bragança. Mem. Not. Pub. Mus. Min. Geol. Univ. Coimbra, 112 (A), Coimbra., p. 247-265.

PEREIRA, D. I. \& AZEVEDO, T. M. (1993a) - Caracterização sedimentológica e geomorfológica dos depósitos de Raña da região de Bragança, com vista à definição das suas condições de génese e evolução, Monografias, 2, Centro de Estudios Medioambientales, Madrid, p.27-39.

PEREIRA, D. I. \& AZEVEDO, T. M. (1993b) - Depósitos de preenchimento das depressões associadas ao acidente de BragançaManteigas, no sector a norte do Douro (Trás-os-Montes, Portugal). Actas da 3." Reunião do Quaternário Ibérico, Coimbra, p. 183-190. 
PERÉZ-GONZÁLEZ, A. (1982)—Neógeno y Cuaternario de la Llanura manchega y sus relaciones com la cuenca del Tajo, Tesis doctoral. Univ. Complutense, Madrid, 787 p.

PERÉZ-GONZÁLEZ, A. \& GALLARDO, J. (1987) - La raña al sur de la Somossierra y Sierra de Ayllón: un piedmonte escalonado del Villafranquiense medio. Geogaceta, 2, p. 29-32.

PIMENTEL, N. (1997) - Terciario da Bacia do Sado, sedimentologia $e$ análise tectono-sedimentar, Tese de douto-ramento, Universidade de Lisboa, 381p.

PIMENTEL, N. \& AZEVEDO, T. (1993) - Os depósitos de raña do Sudoeste Ibérico (Baixo Alentejo ocidental, Portugal), Monografias, 2, Centro de Ciencias Medioambientales, Madrid, p. 59-70.

NIKIFOROVA, K \& ALEKSEEV, M. (1997) - International Geological Correlation Program, Project 41: «Neogene/ Quaternary Boundary». in VAN COUVERING (ed.), The Pleistocene
Boundary and the Beginning of the Ouaternary, World and Regional Geology, 9, Cambridge University Press, p. 3-12.

RACKOCKI, A. (1981)-Alluvial Fans, an attempt at an empirical approach. John Wiley \& Sons.

VAN COWERING, J. (1997) — Preface: the new Pleistocene, in VAN COUVERING (ed.), The Pleistocene Boundary and the Beginning of the Quaternary, World and Regional Geology, 9, Cambridge University Press, p.xi-xvii.

WELLS, S. \& HARVEY, A. (1987) - Sedimentologic and geomorphic variations in storm-generated alluvial fans, Howgill Fell, northwest England. Geological Society of America Bulletin, 98, p. 182-198

ZUBAKOV, V. A. (1990) - Paleoclimates of the Pliocene, in ZUBAKOV e BORZENKOVA (eds.), Global Palaeoclimate of the Late Cenozoic. Developments in Palaeontology and Stratigraphy, 12. Elsevier. 